\title{
EKSISTENSI PEMBANGUNAN MASYARAKAT DAN DESA DI KAWASAN PERKOTAAN KABUPATEN PATI
}

\section{THE EXISTENCE OF COMMUNITY AND VILLAGE DEVELOPMENT IN THE URBAN AREAS OF PATI REGENCY}

\author{
Suroso \\ Badan Perencanaan Pembangunan Daerah Kabupaten Pati \\ Jl. Raya Pati-Kudus Km. 4 Pati. 59163. Jawa Tengah
}

\begin{abstract}
Realizing developed villages is a challenge for village development. This study aimed (1) to identify the existence of village development based on Village development Index (IDM) in the sub-districts having urban areas and (2) to analyze the needs of development based on the village typology. This study applied descriptive-quantitative approaches. This study was conducted in three sub-districts, namely Pati, Juwana, and Tayu. The primary data were obtained through interviews with competent key informants. Meanwhile, the secondary data were collected through related document observations. The study used descriptive analysis. The results of the study showed that the existence of village development in these three sub-districts had IDM growth, but only some villages were able to reach the higher-level during 2017 -2019. The villages in Pati sub-district needed economic development (IKE), but the villages in Juwana and Tayu subdistrict needed environmental development (IKL). Following the national policy, village development should consider the real condition of village typology, potencies and local characteristics.
\end{abstract}

Keywords: urban area, village development index, village development

\begin{abstract}
ABSTRAK
Upaya mewujudkan desa maju merupakan tantangan pembangunan desa. Tujuan penelitian adalah: (1) mengidentifikasi eksistensi pencapaian pembangunan masyarakat dan desa berbasis IDM di Kecamatan yang memiliki kawasan perkotaan; dan (2) menganalisis kebutuhan pembangunan berdasarkan tipologi desa di area studi. Penelitian menggunakan pendekatan deskriptif-kuantitatif. Penelitian dilakukan di Kecamatan Pati, Juwana, dan Tayu yang merupakan kecamatan yang memiliki kawasan perkotaan di Kabupaten Pati. Penelitian menggunakan data primer dan data sekunder. Pengumpulan data primer dilakukan dengan wawancara dengan narasumber yang kompeten. Sementara itu, pengumpulan data sekunder dilakukan dengan mereview dokumen yang relevan. Selanjutnya data yang diperoleh dianalisis secara deskriptif. Hasil penelitian menunjukkan bahwa eksistensi pembanguunan desa di kecamatan yang memiliki kawasan perkotaan mengalami peningkatan IDM tetapi hanya sedikit desa yang mampu mengalami tranformasi tipologi setingkat lebih baik antara kurun waktu tahun 2017-2019. Secara umum pembangunan desa di Kecamatan Pati lebih membutuhkan pembangunan ekonomi (IKE), tetapi pembangunan desa di Kecamatan Juwana dan Tayu lebih membutuhkan pembangunan lingkungan (IKL). Relevan dengan kebijakan nasional, pembangunan desa agar bertitik tolak dari kondisi riil tipologi desa, potensi dan karakteristik lokal desa
\end{abstract}

Kata kunci : kawasan perkotaan, indeks desa pembangunan, pembangunan desa.

\section{PENDAHULUAN}

Upaya peningkatan kesejahteraan masyarakat dan pelayanan publik merupakan tantangan pembangunan Kabupaten Pati yang tercantum dalam visi pembangunan daerah periode tahun 2017-2022 (Bappeda, 2018). Visi pembangunan tersebut merupakan upaya mewujudkan amanat Undang-Undang Nomor 23 tahun 2014 tentang Pemerintah Daerah, Pasal 258 menyebutkan bahwa daerah melaksanakan pembangunan untuk peningkatan dan pemerataan pendapatan masyarakat, kesempatan kerja, lapangan berusaha, meningkatkan akses dan kualitas pelayanan publik dan daya saing daerah. 
Peningkatan kesejahteraan masyarakat dan desa belakangan ini menggunakan tolok ukur Indeks Desa Membangun (IDM). Upaya mewujudkan desa mandiri dan desa maju merupakan tantangan utama dalam pembangunan desa. Indeks Desa Membangun (IDM) dimaksudkan untuk mendukung pencapaian sasaran pembangunan prioritas Rencana Pembangunan Jangka Menengah Nasional (RPJMN) 2015-2019, yaitu mengurangi jumlah desa tertinggal sampai 5.000 desa dan meningkatkan jumlah desa mandiri sedikitnya 2.000 desa di tahun 2019. Sejak diluncurkan kebijakan dana desa, eksistensi desa yang masuk kategori desa mandiri dan desa maju masih relatif kecil. Provinsi Jawa Tengah misalnya, desa yang masuk kategori desa mandiri hanya 21 dari 7.809 $(0,27 \%)$ dan desa maju sebanyak 868 dari 7.809 (11,12\%) (Kemendes PDTT RI, 2015).

Kebijakan menstimulasi pembangunan desa diantaranya dilakukan melalui penerbitan regulasi kebijakan afirmatif sebagai bentuk reorientasi pembangunan melalui tata kelola pembangunan berbasis desa (Irawan, 2017). Regulasi tersebut juga telah memberikan ruang bagi pemerintahan desa dalam pembangunan. Pengambilan keputusan oleh komunitas desa merupakan faktor penting dalam tata kelola pemeritahan desa (Agusta, 2014). Desa sebagai unit administrasi pemerintahan terkecil memegang peranan penting dan diharapkan menjadi titik awal berkembangnya pusat-pusat pertumbuhan perekonomian masyarakat. Pembangunan berbasis desa dilaksanakan dalam rangka intervensi untuk mengurangi kesenjangan kemajuan antara kawasan perdesaan dan perkotaan sebagai akibat dari pembangunan sebelumnya yang cenderung berorientasi pada wilayah perkotaan ( Kemendes PDTT RI, 2015).

Rencana tata ruang wilayah Kabupaten Pati menyebutkan terdapat tiga kecamatan dengan wilayah perkotaan, yaitu Kecamatan Tayu, Pati, dan Juwana (Tatina). Kedekatan dengan kawasan perkotaan yang merupakan pusat pengembangan ekonomi merupakan keuntungan bagi pembangunan kawasan perdesaan di sekitarnya. Desa-desa tersebut berpotensi menjadi desa maju dan mandiri dengan IDM yang lebih baik dibandingkan dengan desa yang benar-benar terletak di kawasan perdesaan. Keberhasilan pembangunan desa di kawasan tersebut, selanjutnya dapat dijadikan percontohan bagi pembangunan desa di kawasan lain. Bagaimana dengan eksistensi pembangunan desa di Kecamatan Tayu, Pati, dan Juwana? Apakah desa-desa di tiga kecamatan tersebut mampu memanfaatkan posisi strategis yang dimiliki untuk mengembangkan desa maju dan desa mandiri? Oleh karena itu, tujuan dari penelitian ini adalah (1) mengidentifikasi pencapaian pembangunan desa berbasis IDM pada kawasan perkotaan; dan (2) menganalisis kebijakan pembangunan desa berdasarkan tipologi desa di area studi.

\section{TINJAUAN PUSTAKA}

Pembangunan masyarakat dan desa saling berkait serta berpengaruh timbal balik. Masyarakat yang berdaya mempengaruhi laju kemajuan pembangunan desa. Sebaliknya, desa yang dikelola dengan baik dapat meningkatkan kesejahteraan masyarakat. Pembangunan masyarakat menurut Theresia (2014) adalah pembangunan yang mengacu kepada kebutuhan masyarakat, direncanakan dan dilaksanakan oleh masyarakat dengan memanfaatkan potensi sumber daya yang dapat diakses oleh masyarakat setempat.

Seiring dengan pesatnya pertambahan penduduk permukiman wilayah perkotaan, slum dan squatter merupakan permasalahan stereotip penting yang butuh untuk segera ditindaklanjuti (Nursyahbani \& Pigawati, 2015; Widjaja, 2013). Penyelesaian permasalahan teknis di permukiman wilayah perkotaan tidak sebatas pada wacana lingkungan kumuh dan liar, akan tetapi lebih menyeluruh mencakup pembangunan yang berwawasan lingkungan (Hamidah dkk., 2016). Kemakmuran rakyat, kelestarian fungsi, dan keseimbangan lingkungan hidup merupakan indikator utama dalam keberlanjutan pembangunan berwawasan lingkungan (Hall \& Pfeiffer, 2013; Jazuli, 2015). Oleh karenanya, Pembangunan berwawasan 
lingkungan perlu memfokuskan pengelolaan potensi sumber daya alam di kawasan tersebut secara terencana, bertanggung jawab, dan sesuai dengan daya dukungnya agar tidak memunculkan problematika degradasi pada kualitas lingkungan hidup dan kehidupan manusianya (Daniels, 2017). Pengelolaan perekonomian sebagai bagian dari pembangunan berwawasan lingkungan perlu mendapat pemikiran lebih ketika permukiman berada di lingkungan perekonomian masif. Percepatan pertumbuhan ekonomi kawasan perkotaan menuntut adanya perubahan atau perkembangan tata ruang berkelanjutan (Daniels, 2017). Untuk dapat mengimbangi kondisi lingkungan, keberadaan kota harus dapat memberi kontribusi positif terhadap lingkungan termasuk peningkatan sosiokultural sejalan dengan pertumbuhan perekonomian (Nazaruddin, 2015).

Pembangunan dari kawasan pinggiran adalah paradigma yang saat ini diterapkan di Indonesia. Oleh karenanya, kebijakan dana desa diterapkan untuk mendukung paradigma pembangunan tersebut. Melalui dana langsung dari APBN dengan skema dana desa, diharapkan pembangunan dan pemberdayaan masyarakat desa lebih optimal karena anggaran langsung dikelola oleh pemerintah desa (Sofianto, 2017). Selanjutnya, capaian pembangunan desa dapat diukur dengan menggunakan Indeks Desa Membangun (IDM).

Hasil pembangunan desa berbasis IDM merupakan komposit dari pembangunan aspek sosial, ekonomi ${ }_{2}$ dan ekologi (Kemendes PDTT RI, 2015). Kementerian Desa, Pembangunan Daerah Ter-tinggal, dan Transmigrasi telah mengembangkan program unggulan berdasar tiga pendekatan yang disebut pilar desa membangun indonesia yakni: (1) jaring komunitas wiradesa; (2) lumbung ekonomi desa; dan (3) lingkar budaya desa.

Pertama, jaring komunitas wiradesa yaitu memperkuat kualitas manusia dengan memperbanyak kesempatan dan pilihan dalam upaya penduduk desa menegakkan hak dan martabatnya, serta meningkatkan kesejahte- raan, baik sebagai individu, keluarga maupun kolektivitas warga desa. Desa membangun dihadapkan pada kenyataan kemiskinan akibat rendahnya produktivitas masyarakat dan rendahnya kualitas lingkungan permukiman desa (Kolopaking, 2011).

Kedua, lumbung ekonomi desa. Potensi sumber daya di desa dapat dikonversi menjadi ekonomi yang di dalamnya melibatkan modal, organisasi ekonomi, terdapat nilai tambah dan menyejahterakan secara ekonomi. Pengembangan lumbung ekonomi desa diharapkan mampu menjawab masalah modal, jaringan serta memiliki informasi yang kuat sehingga organisasi ekonomi yang dikembangkan harus kompatibel dengan hal tersebut.

Indeks Desa Membangun (IDM) sebagai acuan dasar untuk mengukur pencapaian sasaran pembangunan desa. Melalui pengukuran IDM ini, maka desa dapat menjadi instrumen alat ukur capaian pembangunan sehingga diketahui indikator mana yang belum tercapai dan aspek mana yang telah tercapai (Setyobakti, 2017). Dalam konteks pelaksanaan UndangUndang Desa misalnya, BUMDes akan kuat jika dibangun dan dikelola oleh warga desa yang teruji secara nilai dan moral, serta memiliki modal sosial yang kuat, mampu mengembangkan kreasi serta daya untuk menjangkau modal, jaringan, dan informasi.

Ketiga, lingkar budaya desa. Gerakan sosial pembangunan desa tidak hanya tergantung pada inisiasi orang perorang maupun insentif, tapi lebih kepada panggilan kultural. Gerakan pembangunan desa haruslah dilakukan karena kolektivitas, persaudaraan serta kesadaran mau melakukan perubahan secara kolektif. Pembangunan desa hendaknya melampaui kepentingan pribadi. Dana desa dalam konteks memperkuat pembangunan dan pemberdayaan desa, harus dikritisi agar tidak menjadi bentuk ketergantungan baru. Pembangunan desa dimaknai sebagai kerja budaya dengan norma dan moral sebagai pondasinya, sebagai code of conduct, dan dengan demikian perilaku ekonomi dalam kehidupan desa akan mampu menegakkan martabat dan kesejahteraan. 
Peran pemerintah pusat, provinsi, serta kabupaten dalam melakukan pembinaan dan pengawasan penyelenggaraan pemerintahan desa. Meningkatnya wewenang pemerintah desa untuk berinisiatif memutuskan kegiatan dan anggaran pembangunan atau dikenal sebagai kaidah "desa membangun" (Irawan, 2017). Dengan demikian, pembinaan dan pengawasan yang dilakukan tidak lepas dari koridor desentralisasi dan otonomi desa.

Otonomi desa memberikan peluang dalam percepatan pembangunan desa. Mengacu pada konteks pembangunan desa berbasis IDM, tipologi kemajuan desa diklasifikasikan dalam 5 kategori yaitu: desa sangat tertinggal, desa tertinggal, desa berkembang, desa maju dan desa mandiri. Tipologi desa tersebut dibedakan berdasarkan tingkat capaian IDM. Klasifikasi Indeks Desa Membangun (IDM) dengan kriteria: (1) desa sangat tertinggal: $<0,491$; (2) desa tertinggal: > 0,491 dan < 0,599; (3) desa berkembang: $>0,599$ dan <0,707; (4) desa maju: $>0,707$ dan < 0,815; dan (5) desa mandiri: > 0,815 (Kemendes PDTT RI, 2015).

Terkait tipologi desa tersebut, Permendes PDTT No. 22 Tahun 2016 mengatur tentang prioritas pembangunan desa. Pertama, desa tertinggal dan/atau desa sangat tertinggal memprioritaskan kegiatan pembangunan pada dua substansi yaitu: (1) pengadaan, pembangunan, pengembangan, dan pemeliharaan sarana prasarana dasar; (2) pembangunan, pengembangan dan pemeliharaan sarana prasarana ekonomi, serta pengadaan produksi, distribusi, dan pemasaran yang ditujukan untuk mendukung pembentukan usaha ekonomi pertanian berskala produktif, usaha ekonomi pertanian yang difokuskan kepada kebijakan satu desa satu produk unggulan. Selanjutnya, prioritas kegiatan pemberdayaan masyarakat desa untuk merintis lumbung ekonomi desa yang meliputi: (1) pembentukan usaha ekonomi warga dan BUMDes melalui pemberian akses modal, pengelolaan produksi, distribusi dan pemasaran bagi usaha ekonomi pertanian berskala produktif dan usaha ekonomi lainnya yang difokuskan pada kebijakan satu desa satu produk unggulan; dan (2) pembukaan lapangan kerja untuk pemenuhan kebutuhan hidup bagi masyarakat desa.

Kedua, prioritas pembangunan desa bagi desa berkembang adalah: (1) pembangunan, pengembangan dan pemeliharaan infrastruktur ekonomi serta pengadaan sarana prasarana produksi, distribusi dan pemasaran untuk mendukung penguatan usaha ekonomi pertanian berskala produktif, usaha ekonomi untuk ketahanan pangan dan usaha ekonomi lainnya yang difokuskan kepada kebijakan satu desa satu produk unggulan dan (2) pembangunan dan pemeliharaan infrastruktur serta pengadaan sarana prasarana sosial dasar dan lingkungan yang diarahkan pada upaya mendukung pemenuhan akses masyarakat desa terhadap pelayanan sosial dasar dan lingkungan. Selain itu, prioritas pemberdayaan masyarakat desa juga untuk memperkuat lumbung ekonomi desa yang meliputi: (1) penguatan usaha ekonomi warga dan BUMDes melalui pemberian akses modal, pengelolaan produksi, distribusi dan pemasaran bagi usaha ekonomi pertanian berskala produktif, usaha ekonomi yang difokuskan pada kebijakan satu desa satu produk unggulan; (2) peningkatan kualitas dan kuantitas tenaga kerja terampil dan wirausahawan di desa; serta (3) perluasan lapangan kerja untuk pemenuhan kebutuhan hidup masyarakat desa.

Ketiga, desa maju dan/atau desa mandiri memprioritaskan pembangunan pada: (1) pembangunan, pengembangan dan pemeliharaan infrastruktur ekonomi serta pengadaan sarana prasarana produksi, distribusi dan pemasaran untuk mendukung perluasan usaha ekonomi pertanian berskala produktif, usaha ekonomi untuk ketahanan pangan dan usaha ekonomi lainnya yang difokuskan kepada kebijakan satu desa satu produk unggulan; dan (2) pembangunan dan pemeliharaan infrastruktur serta pengadaan sarana prasarana sosial dasar dan lingkungan yang diarahkan untuk mendukung peningkatan pemenuhan akses masyarakat terhadap pelayanan sosial dasar dan lingkungan. Sementara itu, prioritas pemberdayaan masyarakat desa untuk menegakkan lumbung 
ekonomi desa yang meliputi: (1) perluasan usaha ekonomi warga dan BUMDes melalui pemberian akses modal, pengelolaan produksi, distribusi, dan pemasaran bagi usaha ekonomi pertanian berskala produktif, usaha ekonomi untuk ketahanan pangan, serta usaha ekonomi lainnya yang difokuskan kepada kebijakan satu desa satu produk unggulan; (2) peningkatan kualitas dan kuantitas wirausahawan; (3) peningkatan kualitas dan kuantitas tenaga kerja ahli; dan (4) perluasan lapangan kerja bagi masyarakat desa.

\section{METODE PENELITIAN}

Penelitian menggunakan pendekatan deskriptif-kuantitatif. Penelitian ini dilakukan di Kecamatan Pati, Kecamatan Juwana, dan Kecamatan Tayu yang memiliki kawasan perkotaan serta kawasan perdesaan. Penelitian menggunakan data sekunder dan data primer. Pengumpulan data sekunder dilakukan melalui observasi dokumen dari perangkat daerah yang relevan yaitu Dinas Pemberdayaan Masyarakat dan Desa (Dispermades) Kabupaten Pati, serta review penelitian terdahulu yang relevan. Pengumpulan data primer dilakukan dengan wawancara dengan narasumber yang kompeten termasuk pendamping desa, serta tenaga ahli pada Dispermades. Selanjutnya data yang diperoleh dianalisis secara deskriptif.

Indeks Desa Membangun (IDM) merupakan indeks komposit dari dimensi Indeks Ketahanan Sosial (IKS), Indeks Ketahanan Ekonomi (IKE) dan Indeks Ketahanan Lingkungan/ekologi (IKL). Pengukuran masingmasing indeks dinyatakan dalam rumus:

$$
\text { Indeks Variabel }=\quad \frac{\sum \text { Indikator } X}{\text { Nilai Maks }(X)} \ldots
$$

Setiap variabel memiliki sejumlah indikator dan setiap indikator memiliki skor antara 1 sampai dengan 5 dimana semakin tinggi skor mencerminkan tingkat keberhasilan. Setiap skor indikator diakumulasikan untuk menghasilkan skor variabel. Indeks dari setiap variabel digabungkan menjadi indeks komposit, Indeks Desa Membangun (IDM) yang dinyatakan dengan rumus:

$\mathrm{IDM}=(\mathrm{IKS}+\mathrm{IKE}+\mathrm{IKL}) / 3$

IDM : Indeks Desa Membangun

IKS : Indeks Ketahanan Sosial

IKE : Indeks Ketahanan Ekonomi

IKL : Indeks Ketahanan Lingkungan

Pengukuran pembangunan desa dengan cara membandingkan antara capaian Indeks Desa Membangun (IDM) terhadap kriteria IDM yang diklasifikasikan menjadi 5 kategori yaitu: (1) desa sangat tertinggal: < 0,491; (2) desa tertinggal: > 0,491 dan < 0,599; (3) desa berkembang: $>0,599$ dan < 0,707; (4) desa maju: $>0,707$ dan $<0,815$; dan (5) desa mandiri: $>$ 0,815 .

\section{HASIL DAN PEMBAHASAN}

Secara berurutan, hasil dan pembahasan eksistensi pembangunan desa di lokasi penelitian adalah Kecamatan Pati, Kecamatan Juwana, dan Kecamatan Tayu.

\section{Indek Pembangunan Desa di Kecamatan Pati}

Perkembangan pembangunan desa berbasis Indeks Desa Membangun (IDM) antara tahun 2017 dan 2019 di Kecamatan Pati menunjukkan bahwa mayoritas desa memiliki peningkatan indeks tetapi hanya 3 desa yang mengalami transformasi peningkatan tipologi. Pertama, Desa Puri memiliki indeks 0,8030 masuk kategori desa maju tahun 2017 meningkat indeknya menjadi 0,8640 masuk kategori desa mandiri tahun 2019. Kedua, Desa Ngarus memiliki indeks 0,6950 masuk kategori desa berkembang di tahun 2017 meningkat menjadi 0,7735 masuk kategori desa maju di tahun 2019. Ketiga, Desa Sinoman memiliki indeks 0,5990 masuk kategori desa tertinggal tahun 2017 dan meningkat indeksnya menjadi 0,6176 masuk kategori desa berkembang tahun 2019. Perkembangan pembangunan desa di Kecamatan Pati ditunjukkan Tabel 1. 
Tabel 1.

Perkembangan Indeks Pembangunan Desa di Kecamatan Pati

\begin{tabular}{|c|c|c|c|c|c|}
\hline \multirow{2}{*}{ Desa } & \multicolumn{2}{|r|}{2017} & \multicolumn{2}{|c|}{2019} & \multirow{2}{*}{ Perkembangan } \\
\hline & IDM & Kategori & IDM & Kategori & \\
\hline Panjunan & 0,6660 & Berkembang & 0,6933 & Berkembang & Tetap \\
\hline Gajahmati & 0,7680 & Maju & 0,7848 & Maju & Tetap \\
\hline Mustokoharjo & 0,7590 & Maju & 0,7681 & Maju & Tetap \\
\hline Semampir & 0,7130 & Maju & 0,7163 & Maju & Tetap \\
\hline Blaru & 0,7140 & Maju & 0,7695 & Maju & Tetap \\
\hline Plangitan & 0,7740 & Maju & 0,7908 & Maju & Tetap \\
\hline Puri & 0,8030 & Maju & 0,8640 & Mandiri & Naik \\
\hline Winong & 0,7460 & Maju & 0,7648 & Maju & Tetap \\
\hline Ngarus & 0,6950 & Berkembang & 0,7735 & Maju & Naik \\
\hline Sidoharjo & 0,7240 & Maju & 0,7335 & Maju & Tetap \\
\hline Sarirejo & 0,7200 & Maju & 0,8041 & Maju & Tetap \\
\hline Geritan & 0,6910 & Berkembang & 0,6941 & Berkembang & Tetap \\
\hline Dengkek & 0,6700 & Berkembang & 0,6717 & Berkembang & Tetap \\
\hline Sugiharjo & 0,6130 & Berkembang & 0,6256 & Berkembang & Tetap \\
\hline Widorokandang & 0,6850 & Berkembang & 0,6848 & Berkembang & Tetap \\
\hline Payang & 0,6240 & Berkembang & 0,6497 & Berkembang & Tetap \\
\hline Kutoharjo & 0,7160 & Maju & 0,7860 & Maju & Tetap \\
\hline Sidokerto & 0,7210 & Maju & 0,7221 & Maju & Tetap \\
\hline Mulyoharjo & 0,6400 & Berkembang & 0,6822 & Berkembang & Tetap \\
\hline Tambaharjo & 0,8470 & Mandiri & 0,8424 & Mandiri & Tetap \\
\hline Tambahsari & 0,6550 & Berkembang & 0,6697 & Berkembang & Tetap \\
\hline Ngepungrejo & 0,6730 & Berkembang & 0,7060 & Berkembang & Tetap \\
\hline Purworejo & 0,6220 & Berkembang & 0,6676 & Berkembang & Tetap \\
\hline Sinoman & 0,5990 & Tertinggal & 0,6176 & Berkembang & Naik \\
\hline
\end{tabular}

Sumber: Dispermades Kabupaten Pati, 2019

Berdasarkan Tabel 1 dapat dinyatakan bahwa pembangunan desa berbasis IDM menunjukkan: (a) terdapat 11 dari 24 desa (45,83\%) masuk kategori desa berkembang dengan indeks antara 0,5990 dan 0,7070; (b) terdapat 11 dari 24 desa $(45,83 \%)$ masuk kategori desa maju dengan indeks antara 0,7070 dan 0,8150; dan (c) terdapat 2 dari 24 desa $(8,33 \%)$ masuk kategori desa mandiri dengan indeks di atas 0,8150 . Desa yang masuk kategori desa mandiri yaitu Desa Puri dan Desa Tambaharjo. Desa dengan IDM tertinggi adalah Desa Puri $(0,8640)$, sementara IDM terendah berada di Desa Sinoman (0,6176). Perbandingan data IDM tahun 2017 dan 2019, menunjukkan bahwa sebagian besar desa di Kecamatan Pati mengalami peningkatan skor IDM. Peningkatan skor tertinggi ditemukan di
Desa Sarirejo (0,0841), disusul oleh Desa Ngarus dan Kutoharjo dengan peningkatan 0,0785 dan 0,0700 poin. Terdapat dua desa yang mengalami penurunan skor IDM, yaitu Desa Tambaharjo dan Desa Widorokandang dengan penurunan 0,0046 dan 0,0002 poin.

Pembangunan desa dilakukan dengan mempertimbangkan tipologi desa dan memprioritaskan komponen indeks yang masih lemah/rendah. Perbandingan rata-rata ketiga aspek IDM menunjukkan bahwa komponen IDM dengan skor tertinggi di Kecamatan Pati adalah Indeks Ketahanan Sosial (IKS) dengan rata-rata skor 0,7894; sedangkan skor terendah adalah Indeks Ketahanan Ekonomi (IKE) dengan nilai 0,6909. Gambaran lengkap komponen IDM setiap desa di Kecamatan Pati ditampilkan pada Tabel 2. 
Jurnal Litbang Vol. XV No. 2 Bulan Desember 2019 Hal 77-90

Tabel 2.

Eksistensi Indeks Desa Membangun (IDM) di Kecamatan Pati Tahun 2019

\begin{tabular}{|c|c|c|c|c|c|c|}
\hline \multirow{2}{*}{ Desa } & \multicolumn{3}{|c|}{ Komponen IDM } & \multirow{2}{*}{$\begin{array}{c}\text { Rata-rata } \\
\text { IDM }\end{array}$} & \multirow{2}{*}{$\begin{array}{c}\text { Kategori } \\
\text { Desa }\end{array}$} & \multirow{2}{*}{$\begin{array}{c}\text { Indeks } \\
\text { Terkecil }\end{array}$} \\
\hline & IKS & IKE & IKL & & & \\
\hline Panjunan & 0,6800 & 0,7333 & 0,6667 & 0,6933 & Berkembang & IKL \\
\hline Gajahmati & 0,7543 & 0,7333 & 0,8667 & 0,7848 & Maju & IKE \\
\hline Mustokoharjo & 0,7543 & 0,6167 & 0,9333 & 0,7681 & Maju & IKE \\
\hline Semampir & 0,7657 & 0,7833 & 0,6000 & 0,7163 & Maju & IKL \\
\hline Blaru & 0,7086 & 0,7333 & 0,8667 & 0,7695 & Maju & IKS \\
\hline Plangitan & 0,8057 & 0,7000 & 0,8667 & 0,7908 & Maju & IKE \\
\hline Puri & 0,9086 & 0,8167 & 0,8667 & 0,8640 & Mandiri & IKE \\
\hline Winong & 0,7943 & 0,8333 & 0,6667 & 0,7648 & Maju & IKL \\
\hline Ngarus & 0,7371 & 0,7167 & 0,8667 & 0,7735 & Maju & IKE \\
\hline Sidoharjo & 0,8171 & 0,7833 & 0,6000 & 0,7335 & Maju & IKL \\
\hline Sarirejo & 0,8457 & 0,7667 & 0,8000 & 0,8041 & Maju & IKE \\
\hline Geritan & 0,7657 & 0,6500 & 0,6667 & 0,6941 & Berkembang & IKE \\
\hline Dengkek & 0,7486 & 0,6667 & 0,6000 & 0,6717 & Berkembang & IKL \\
\hline Sugiharjo & 0,7600 & 0,5833 & 0,5333 & 0,6256 & Berkembang & IKL \\
\hline Widorokandang & 0,7543 & 0,7000 & 0,6000 & 0,6848 & Berkembang & IKL \\
\hline Payang & 0,7657 & 0,5833 & 0,6000 & 0,6497 & Berkembang & IKE \\
\hline Kutoharjo & 0,8914 & 0,7333 & 0,7333 & 0,7860 & Maju & IKE/L \\
\hline Sidokerto & 0,7829 & 0,7167 & 0,6667 & 0,7221 & Maju & IKL \\
\hline Mulyoharjo & 0,8800 & 0,5667 & 0,6000 & 0,6822 & Berkembang & IKE \\
\hline Tambaharjo & 0,9771 & 0,8833 & 0,6667 & 0,8424 & Mandiri & IKL \\
\hline Tambahsari & 0,7257 & 0,6167 & 0,6667 & 0,6697 & Berkembang & IKE \\
\hline Ngepungrejo & 0,8514 & 0,6000 & 0,6667 & 0,7060 & Berkembang & IKE \\
\hline Purworejo & 0,7029 & 0,5667 & 0,7333 & 0,6676 & Berkembang & IKE \\
\hline Sinoman & 0,7029 & 0,5500 & 0,6000 & 0,6176 & Berkembang & IKE \\
\hline
\end{tabular}

Sumber: Dispermades Kabupaten Pati, 2019

Terdapat 13 desa di Kecamatan Pati dengan nilai IKE paling kecil dibandingkan IKS dan IKL. Selanjutnya, terdapat 9 desa dengan nilai IKL paling kecil dibandingkan IKS dan IKS serta terdapat satu desa dengan nilai IKS paling rendah dibandingkan IKE dan IKL. Terdapat perbedaan nilai komponen IKM di dua desa yang dikategorikan sebagai desa mandiri, yaitu Desa Puri dan Desa Tambaharjo. Komponen IDM dengan nilai terendah di Desa Puri adalah IKE $(0,8167)$, sementara di Desa Tambaharjo nilai terendah adalah IKL $(0,6667)$. Oleh karenanya, dapat dinyatakan bahwa pembangunan desa di Kecamatan Pati agar memprioritaskan pembangunan ekonomi dan sarana prasarana yang mendukung dengan tanpa mengabaikan pembangunan sosial dan lingkungan.

\section{Indek Pembangunan Desa di Kecamatan Juwana}

Kecamatan Juwana memiliki 29 desa. Rata-rata nilai IDM Desa di Kecamatan Juwana adalah 0,6942 dimana nilai tersebut meningkat sebesar 0,0268 dibandingkan rata-rata IDM di tahun 2019. Sebagian besar desa mengalami peningkatan nilai IDM, namun hanya 3 desa yang mengalami transformasi peningkatan tipologi yaitu Desa Margomulyo, Desa Pajeksan, dan Desa Bajomulyo.

Desa Margomulyo memiliki indeks 0,7070 (desa berkembang) meningkat menjadi 0,7084 (desa maju). Kedua, Desa Pajeksan memiliki indeks 0,6070 (desa berkembang) meningkat menjadi 0,7586 (desa maju). Ketiga, Desa Bajomulyo memiliki indeks 0,6860 (desa berkembang) meningkat menjadi 0,8135 (desa maju). Eksistensi pembangunan desa berbasis IDM di Kecamatan Juwana tahun 2019, menunjukkan bahwa terdapat 24 desa $(82,76 \%)$ yang masuk kategori desa berkembang dan terdapat 5 desa $(12,24 \%)$ masuk kategori desa maju. Gambaran pembangunan desa di Kecamatan Juwana ditampilkan pada Tabel 3. 
Tabel 3.

Perkembangan Indeks Pembangunan Desa di Kecamatan Juwana

\begin{tabular}{|c|c|c|c|c|c|}
\hline \multirow{2}{*}{ Desa } & \multicolumn{2}{|r|}{2017} & \multicolumn{2}{|r|}{2019} & \multirow{2}{*}{ Perkembangan } \\
\hline & IDM & Kategori & IDM & Kategori & \\
\hline Sejomulyo & 0,6440 & Berkembang & 0,6776 & Berkembang & Tetap \\
\hline Bringin & 0,6830 & Berkembang & 0,6900 & Berkembang & Tetap \\
\hline Ketip & 0,6790 & Berkembang & 0,6959 & Berkembang & Tetap \\
\hline Pekuwon & 0,6210 & Berkembang & 0,6660 & Berkembang & Tetap \\
\hline Karang & 0,6330 & Berkembang & 0,6438 & Berkembang & Tetap \\
\hline Karangrejo & 0,7050 & Berkembang & 0,7033 & Berkembang & Tetap \\
\hline Bumirejo & 0,6160 & Berkembang & 0,6292 & Berkembang & Tetap \\
\hline Kedungpancing & 0,6220 & Berkembang & 0,6846 & Berkembang & Tetap \\
\hline Jepuro & 0,7020 & Berkembang & 0,6960 & Berkembang & Tetap \\
\hline Tluwah & 0,6970 & Berkembang & 0,6983 & Berkembang & Tetap \\
\hline Doropayung & 0,7250 & Maju & 0,7959 & Maju & Tetap \\
\hline Mintomulyo & 0,6820 & Berkembang & 0,6881 & Berkembang & Tetap \\
\hline Gadingrejo & 0,6820 & Berkembang & 0,7029 & Berkembang & Tetap \\
\hline Margomulyo & 0,7070 & Berkembang & 0,7084 & Maju & Naik \\
\hline Langgenharjo & 0,7000 & Berkembang & 0,6813 & Berkembang & Tetap \\
\hline Genengmulyo & 0,6460 & Berkembang & 0,6888 & Berkembang & Tetap \\
\hline Agungmulyo & 0,6610 & Berkembang & 0,6629 & Berkembang & Tetap \\
\hline Bakaran Kulon & 0,6940 & Berkembang & 0,7021 & Berkembang & Tetap \\
\hline Bakaran Wetan & 0,6770 & Berkembang & 0,6513 & Berkembang & Tetap \\
\hline Dukutalit & 0,6860 & Berkembang & 0,6892 & Berkembang & Tetap \\
\hline Growong Kidul & 0,6440 & Berkembang & 0,6752 & Berkembang & Tetap \\
\hline Growong Lor & 0,6810 & Berkembang & 0,6986 & Berkembang & Tetap \\
\hline Kauman & 0,7250 & Maju & 0,7386 & Maju & Tetap \\
\hline Pajeksan & 0,6070 & Berkembang & 0,7586 & Maju & Naik \\
\hline Kudukeras & 0,6840 & Berkembang & 0,6899 & Berkembang & Tetap \\
\hline Kebonsawahan & 0,6420 & Berkembang & 0,6633 & Berkembang & Tetap \\
\hline Bajomulyo & 0,6140 & Berkembang & 0,8135 & Maju & Naik \\
\hline Bendar & 0,6100 & Berkembang & 0,6390 & Berkembang & Tetap \\
\hline Trimulyo & 0,6860 & Berkembang & 0,6994 & Berkembang & Tetap \\
\hline
\end{tabular}

Sumber: Dispermades Kabupaten Pati, 2019

Juwana berada di wilayah pesisir. Pada umumnya, wilayah pesisir berada di bawah tekanan penduduk yang tinggi karena proses urbanisasi yang cepat (Khairunnisa dkk., 2017). Wilayah pesisir yang banyak dikunjungi wisatawan meningkatkan kegiatan ekonomi (Lakshmi \& Shaji, 2016). Menurut Notteboom \& Rodrigue (2005), model pengembangan pelabuhan untuk wilayah pesisir yang dikenal dengan regionalisasi pelabuhan. Terdapat model lain yaitu terminalisasi yang berkaitan dengan cara mendapatkan barang langsung ke pelanggan secepat mungkin atau memberikan nilai tambah dalam sistem distribusi.

Identifikasi terhadap setiap komponen IDM menunjukkan nilai rata-rata tertinggi di Kecamatan Juwana adalah Indeks Ketahanan
Sosial $(0,7682)$, sementara komponen dengan rata-rata terendah adalah IKL dengan nilai 0,6460 (Tabel 4). Terdapat 1 desa dengan IKL sebagai komponen terendah (3,45\%). Desa dengan IKE sebagai komponen dengan nilai terendah berjumlah 11 desa $(37,93 \%)$ dan desa dengan IKL sebagai komponen dengan nilai terendah berjumlah 15 desa $(51,72 \%)$.

Berdasarkan kondisi tersebut, sebagian besar desa di Kecamatan Juwana lemah dalam pembangunan lingkungan. Upaya pengembangan lingkungan wilayah pesisir hendaknya disertai kebijakan yang tepat. Analisis terhadap kebijakan tersebut diharapkan menghasilkan informasi yang relevan sehingga termanfaatkan dalam pememecahan masalah dan arah tindakan yang lebih baik (Dunn, 2013). 
Tabel 4.

Eksistensi Indeks Desa Membangun (IDM) di Kecamatan Juwana Tahun 2019

\begin{tabular}{|c|c|c|c|c|c|c|}
\hline \multirow{2}{*}{ Desa } & \multicolumn{3}{|c|}{ Indek Desa Membangun } & \multirow{2}{*}{$\begin{array}{c}\text { Rata-rata } \\
\text { IDM }\end{array}$} & \multirow{2}{*}{$\begin{array}{c}\text { Kategori } \\
\text { IDM }\end{array}$} & \multirow{2}{*}{$\begin{array}{c}\text { Indeks } \\
\text { Terkecil }\end{array}$} \\
\hline & IKS & IKE & IKL & & & \\
\hline Sejomulyo & 0,7829 & 0,5833 & 0,6667 & 0,6776 & Berkembang & IKE \\
\hline Bringin & 0,7200 & 0,7500 & 0,6000 & 0,6900 & Berkembang & IKL \\
\hline Ketip & 0,7543 & 0,6667 & 0,6667 & 0,6959 & Berkembang & IKE/IKL \\
\hline Pekuwon & 0,7314 & 0,6667 & 0,6000 & 0,6660 & Berkembang & IKL \\
\hline Karang & 0,7314 & 0,5333 & 0,6667 & 0,6438 & Berkembang & IKE \\
\hline Karangrejo & 0,7600 & 0,6833 & 0,6667 & 0,7033 & Berkembang & IKL \\
\hline Bumirejo & 0,7543 & 0,6667 & 0,4667 & 0,6292 & Berkembang & IKL \\
\hline Kedungpancing & 0,7371 & 0,5167 & 0,8000 & 0,6846 & Berkembang & IKE \\
\hline Jepuro & 0,7714 & 0,6500 & 0,6667 & 0,6960 & Berkembang & IKE \\
\hline Tluwah & 0,8114 & 0,6167 & 0,6667 & 0,6983 & Berkembang & IKE \\
\hline Doropayung & 0,7543 & 0,7667 & 0,8667 & 0,7959 & Maju & IKS \\
\hline Mintomulyo & 0,7143 & 0,5500 & 0,8000 & 0,6881 & Berkembang & IKE \\
\hline Gadingrejo & 0,7086 & 0,5333 & 0,8667 & 0,7029 & Berkembang & IKE \\
\hline Margomulyo & 0,7086 & 0,6833 & 0,7333 & 0,7084 & Maju & IKE \\
\hline Langgenharjo & 0,8280 & 0,6160 & 0,6000 & 0,6813 & Berkembang & IKL \\
\hline Genengmulyo & 0,7829 & 0,6167 & 0,6667 & 0,6888 & Berkembang & IKE \\
\hline Agungmulyo & 0,7886 & 0,5333 & 0,6667 & 0,6629 & Berkembang & IKE \\
\hline Bakaran Kulon & 0,8229 & 0,7500 & 0,5333 & 0,7021 & Berkembang & IKL \\
\hline Bakaran Wetan & 0,7540 & 0,6000 & 0,6000 & 0,6513 & Berkembang & IKE/IKL \\
\hline Dukutalit & 0,8343 & 0,6333 & 0,6000 & 0,6892 & Berkembang & IKL \\
\hline Growong Kidul & 0,7257 & 0,7000 & 0,6000 & 0,6752 & Berkembang & IKL \\
\hline Growong Lor & 0,8457 & 0,8500 & 0,4000 & 0,6986 & Berkembang & IKL \\
\hline Kauman & 0,7657 & 0,7833 & 0,6667 & 0,7386 & Maju & IKL \\
\hline Pajeksan & 0,9257 & 0,6833 & 0,6667 & 0,7586 & Maju & IKL \\
\hline Kudukeras & 0,7029 & 0,7667 & 0,6000 & 0,6899 & Berkembang & IKL \\
\hline Kebonsawahan & 0,6570 & 0,8000 & 0,5330 & 0,6633 & Berkembang & IKL \\
\hline Bajomulyo & 0,8571 & 0,7833 & 0,8000 & 0,8135 & Maju & IKE \\
\hline Bendar & 0,8171 & 0,6333 & 0,4667 & 0,6390 & Berkembang & IKL \\
\hline Trimulyo & 0,7314 & 0,7667 & 0,6000 & 0,6994 & Berkembang & IKL \\
\hline
\end{tabular}

Sumber: Dispermades Kabupaten Pati, 2019

\section{Indek Pembangunan Desa di Kecamatan Tayu}

Kecamatan Tayu memiliki 21 Desa. Data IDM tahun 2019 menunjukkan terdapat 12 desa masuk kategori desa berkembang dan 9 desa masuk kategori desa maju. Pembangunan desa berbasis IDM antara tahun 2017 dan 2019 di Kecamatan Tayu menunjukkan bahwa sebagian besar desa mengalami peningkatan skor IDM. Peningkatan nilai IDM tertinggi berada di Desa Kedungsari dengan peningkatan skor sebesar 0,0667 diikuti oleh Desa Sendangrejo $(0,0560)$ dan Desa Tayu Kulon $(0,0416)$. Sementara itu terdapat satu desa yang mengalami penurunan skor IDM yaitu Desa Dororejo dengan penurunan sebesar 0,0001 .
Terdapat 3 desa yang mengalami transformasi peningkatan tipologi desa yaitu Desa Kedungsari, Desa Sendangrejo, dan Desa Jepat Lor. Desa Kedungsari memiliki indeks 0,5720 masuk tipologi desa tertinggal di tahun 2017 dan indeks meningkat menjadi 0,6387 masuk desa berkembang di tahun 2019. Desa Sendangrejo memiliki indeks 0, 6570 masuk tipologi desa berkembang tahun 2017 dan indeks meningkat menjadi 0,7130 masuk desa maju. Desa Jepat Lor memiliki indeks 0,7060 masuk tipologi desa berkembang tahun 2017 dan indeks meningkat menjadi 0,7110 masuk desa maju pada tahun 2019. Gambaran perkembangan pembangunan desa di Kecamatan Tayu ditampilkan pada Tabel 5. 
Tabel 5.

Perkembangan Indeks Pembangunan Desa di Kecamatan Tayu

\begin{tabular}{lclclc}
\hline \multirow{1}{*}{ Desa } & \multicolumn{2}{c}{$\mathbf{2 0 1 7}$} & \multicolumn{2}{c}{ 2019 } & \multirow{2}{*}{ Perkembangan } \\
\cline { 2 - 5 } & IDM & Kategori & IDM & Kategori & \\
\hline Pondowan & 0,6060 & Berkembang & 0,6449 & Berkembang & Tetap \\
Kedungsari & 0,5720 & Tertinggal & 0,6387 & Berkembang & Naik \\
Margomulyo & 0,6670 & Berkembang & 0,6759 & Berkembang & Tetap \\
Pakis & 0,6610 & Berkembang & 0,6837 & Berkembang & Tetap \\
Sendangrejo & 0,6570 & Berkembang & 0,7130 & Maju & Naik \\
Jepat Kidul & 0,6750 & Berkembang & 0,6811 & Berkembang & Tetap \\
Tunggulsari & 0,6330 & Berkembang & 0,6557 & Berkembang & Tetap \\
Jepat Lor & 0,7060 & Berkembang & 0,7110 & Maju & Naik \\
Tendas & 0,7240 & Maju & 0,7281 & Maju & Tetap \\
Keboromo & 0,7990 & Maju & 0,8005 & Maju & Tetap \\
Sambiroto & 0,6720 & Berkembang & 0,6811 & Berkembang & Tetap \\
Tayu Wetan & 0,7740 & Maju & 0,7782 & Maju & Tetap \\
Tayu Kulon & 0,7470 & Maju & 0,7886 & Maju & Tetap \\
Pundenrejo & 0,7580 & Maju & 0,7801 & Maju & Tetap \\
Kedungbang & 0,6380 & Berkembang & 0,6681 & Berkembang & Tetap \\
Bendokaton Kdl & 0,6420 & Berkembang & 0,6530 & Berkembang & Tetap \\
Purwokerto & 0,7350 & Maju & 0,7499 & Maju & Tetap \\
Bulungan & 0,6920 & Berkembang & 0,6946 & Berkembang & Tetap \\
Luwang & 0,7460 & Maju & 0,7586 & Maju & Tetap \\
Dororejo & 0,6900 & Berkembang & 0,6899 & Berkembang & Tetap \\
Kalikalong & 0,6920 & Berkembang & 0,7046 & Berkembang & Tetap \\
\hline
\end{tabular}

Sumber: Dispermades Kabupaten Pati, 2019

Analisis selanjutnya adalah pengamatan tipologi desa berdasarkan komponen IDM. Komponen dengan rata-rata nilai tertinggi di Kecamatan Tayu adalah Indeks Ketahanan Sosial atau IKS $(0,7722)$, sedangkan komponen dengan nilai terendah adalah Indeks Ketahanan Lingkungan/IKL $(0,6667)$. Tahun 2019, terdapat 11 dari 21 desa di Kecamatan Tayu yang memiliki IKL lebih rendah dibandingkan IKE dan IKS. Sementara itu, terdapat 10 desa yang memiliki IKE lebih rendah dibandingkan IKL dan IKS. Oleh karena itu, dapat dinyatakan bahwa sebagian besar desa di Kecamatan Tayu memiliki kelemahan pada pembangunan aspek lingkungan. Gambaran kondisi pembangunan desa di Kecamatan Tayu berdasarkan komponen IDM ditampilkan pada Tabel 6.
Permasalahan lingkungan diantaranya disebabkan karena perilaku masyarakat seperti pembakaran sampah sembarangan. Perilaku pembakaran sampah secara terbuka sering dilakukan masyarakat perdesaan. Pembakaran sampah merupakan cara pengelolaan sampah yang mudah dan murah untuk menghilangkan sampah. Namun pembakaran sampah memberikan dampak negatif bagi lingkungan dan kesehatan (Wahyudi, 2019). Sampah perlu dikelola dengan baik termasuk sampah yang timbul dari budidaya tanaman. Budidaya tanaman menimbulkan dampak negatif terhadap lingkungan maka perlu upaya untuk meminimalisasi dampak negatif tersebut melalui efisiensi konsumsi energi, konsumsi sumber daya alam (SDA), serta pengelolaan limbah dan emisi (Astuti, 2019). 
Tabel 6.

Eksistensi Indeks Desa Membangun (IDM) di Kecamatan Tayu

\begin{tabular}{lcccclc}
\hline \multirow{2}{*}{ Desa } & \multicolumn{3}{c}{ Komponen IDM } & Rata-rata & Kategori & Indeks \\
\cline { 2 - 4 } IDM & IKS & IKE & IKL & IDM & Terkecil \\
\hline Pondowan & 0,8514 & 0,6167 & 0,4667 & 0,6449 & Berkembang & IKL \\
Kedungsari & 0,7829 & 0,7333 & 0,4000 & 0,6387 & Berkembang & IKL \\
Margomulyo & 0,7943 & 0,6333 & 0,6000 & 0,6759 & Berkembang & IKL \\
Pakis & 0,8343 & 0,7500 & 0,4667 & 0,6837 & Berkembang & IKL \\
Sendangrejo & 0,8057 & 0,7333 & 0,6000 & 0,7130 & Maju & IKL \\
Jepat Kidul & 0,7600 & 0,8167 & 0,4667 & 0,6811 & Berkembang & IKL \\
Tunggulsari & 0,8171 & 0,4167 & 0,7333 & 0,6557 & Berkembang & IKE \\
Jepat Lor & 0,7829 & 0,7500 & 0,6000 & 0,7110 & Maju & IKL \\
Tendas & 0,8343 & 0,6833 & 0,6667 & 0,7281 & Maju & IKL \\
Keboromo & 0,8514 & 0,8167 & 0,7333 & 0,8005 & Maju & IKL \\
Sambiroto & 0,7600 & 0,8167 & 0,4667 & 0,6811 & Berkembang & IKL \\
Tayu Wetan & 0,8514 & 0,6833 & 0,8000 & 0,7782 & Maju & IKE \\
Tayu Kulon & 0,7657 & 0,7333 & 0,8667 & 0,7886 & Maju & IKE \\
Pundenrejo & 0,8571 & 0,6833 & 0,8000 & 0,7801 & Maju & IKE \\
Kedungbang & 0,7543 & 0,5833 & 0,6667 & 0,6681 & Berkembang & IKE \\
Bendokaton Kidul & 0,7257 & 0,5667 & 0,6667 & 0,6530 & Berkembang & IKE \\
Purwokerto & 0,7829 & 0,6000 & 0,8667 & 0,7499 & Maju & IKE \\
Bulungan & 0,8171 & 0,6000 & 0,6667 & 0,6946 & Berkembang & IKE \\
Luwang & 0,7257 & 0,6833 & 0,8667 & 0,7586 & Maju & IKE \\
Dororejo & 0,7029 & 0,5667 & 0,8000 & 0,6899 & Berkembang & IKE \\
Kalikalong & 0,6971 & 0,6167 & 0,8000 & 0,7046 & Berkembang & IKE \\
\hline
\end{tabular}

Sumber: Dispermades Kabupaten Pati, 2019

\section{KESIMPULAN DAN SARAN}

\section{Kesimpulan}

Eksistensi pembangunan desa berbasis IDM di tiga kecamatan yang memiliki wilayah perkotaan, yaitu Tayu, Pati, dan Juwana (Tatina) memiliki peningkatan indeks dan transformasi tipologi beberapa desa antara tahun 2017 sampai 2019. Terdapat 3 desa di Kecamatan Pati yang mentransformasi tipologi desa setingkat lebih baik, yaitu Desa Puri, Ngarus, dan Sinoman. Kecamatan Juwana memiliki 3 desa yang mampu mentransformasi tipologi desa menjadi setingkat lebih baik, yaitu Desa Margomulyo, Pajeksan, dan Desa Bajomulyo. Sementara itu, Kecamatan Tayu memiliki 3 desa yang mampu bertransformasi setingkat lebih baik, yaitu Desa Kedungsari, Sendangrejo, dan Jepat Lor.
Pembangunan desa di Kecamatan Pati, Juwana, dan Tayu memiliki kekuatan di aspek sosial yang ditunjukkan dengan tingginya indeks IKS jika dibandingkan dengan indeks IKE dan IKL. Sementara untuk kelemahan, terdapat perbedaan. Pembangunan desa di Kecamatan Pati memiliki kelemahan dalam aspek ekonomi, sementara di Kecamatan Juwana dan Tayu memiliki kelemahan pembangunan desa di aspek lingkungan.

\section{Saran}

Pembangunan desa hendaknya relevan dengan arah kebijakan nasional, dimana arah pembangunan sebaiknya bertitik tolak dari kondisi tipologi, potensi serta karakteristik lokal desa. Selanjutnya, pembangunan desa seharusnya ditujukan untuk meningkatkan kesejahteraan masyarakat desa serta kualitas hidup 
Masyarakat. Selain itu, pembangunan desa juga diarahkan guna menanggulangi kemiskinan. Pemberdayaan masyarakat desa yang ditujukan untuk meningkatkan kapasitas dan kapabilitas masyarakat desa dapat dilakukan dengan mendayagunakan potensi dan sumber dayanya sendiri sehingga desa dapat menghidupi dirinya secara mandiri.

\section{DAFTAR PUSTAKA}

Agusta, I. (2014). Indeks Kemandirian Desa: Metode, Hasil, dan Alokasi Program Pembangunan. Jakarta: Yayasan Pustaka Obor Indonesia.

Astuti, A. D. (2019). Analisis Potensi Dampak Lingkungan dari Budidaya Tebu Menggunakan Pendekatan Life Cycle Assessment (LCA). Jurnal Litbang: Media Informasi Penelitian, Pengembangan dan IPTEK, 15 (1), 51-64.

Badan Perencanaan Pembangunan Daerah Kabupaten Pati. (2018). Rencana Pembangunan Jangka Menengah Kabupaten Pati. Pati: Bappeda Pati.

Daniels, T. (2017). Environmental Planning Handbook. Oxon: Routledge.

Dunn, W. N. (2013). Pengantar analisis kebijakan publik. Yogyakarta: UGM Press.

Hall, P., \& Pfeiffer, U. (2013). Urban Future 21: A Global Agenda for Twenty-First Century Cities. London: Routledge.

Hamidah, N., Rijanta, R., Setiawan, B., \& Marfai, M. A. (2016). Kampung Sebagai Model Permukiman Berkelanjutan. INERSIA, XII (2), 114-124.

Irawan, N. (2017). Tata Kelola Pemerintahan Desa Era UU Desa. Jakarta: Yayasan Pustaka Obor Indonesia.

Jazuli, A. (2015). Dinamika Hukum Lingkungan Hidup dan Sumber Daya Alam dalam Rangka Pembangunan Berkelanjutan. Jurnal Rechtsvinding, 4(2), 181-197.
Khairunnisa, Kusumastanto, T., Fahrudin, A. (2017). Penilaian Ekonomi Wisata Pesisir Kawasan Carocok Painan, Kabupaten Pesisir Selatan, Sumatera Barat. Jurnal Ekonomi dan Pembangunan Indonesia, 18 (1), 1-21.

Kementerian Pembangunan Desa, Pembangunan Daerah Tertinggal, dan Transmigrasi (2015). Indeks Desa Membangun. Jakarta: Kemendes PDTT.

Kolopaking, L. M. (2011). Peningkatan Kapasitas dan Penguatan Struktur Kelembagaan Otonomi Desa menuju Desa 2030. Bogor: P4W, IPB, Bogor.

Lakshmi, S. R., \& Shaji, T. L. (2016). Transformation of Coastal Settlements Due to Tourism. Procedia Technology, 24, 16681680. https://doi.org/10.1016/ j.protcy.2016.05.188.

Notteboom, T. E., \& Rodrigue, J. P. (2005). Port regionalization: toward a new phase in port development. Maritime Policy \& Management, 32(3), 297-313.

Nursyahbani, R., \& Pigawati, B. (2015). Kajian Karakteristik Kawasan Pemukiman Kumuh di Kampung Kota (Studi Kasus: Kampung Gandekan Semarang). Teknik PWK, 4(2), 267-281.

Peraturan Menteri Desa, Pembangunan Daerah Tertinggal, dan Transmigrasi Nomor 22 Tahun 2016 tentang Penetapan Prioritas Penggunaan Dana Desa Tahun 2017.

Rodrigue, J. P., \& Notteboom, T. (2009). The Terminalization of Supply Chains: Reassessing the Role of terminals in Port/ Hinterland Logistical Relationships. Maritime Policy \& Management, 36(2), 165183.

Setyobakti, H. M. (2017). Identifikasi Masalah dan Potensi Desa Berbasis Indeks Desa Membangun (IDM) di Desa Gondowangi Kecamatan Wagir Kabupaten Malang. Jurnal Penelitian Ilmu Ekonomi WIGA, 7 (1), 1-14. 
Sofianto, A. (2017). Kontribusi Dana Desa terhadap Pembangunan dan Pemberdayaan Masyarakat di Kebumen dan Pekalongan. Matra Pembaruan Daerah (Bappeda) Provinsi Jawa Tengah. 1(1), 23-32.

Theressia, A. (2014). Pembangunan Berbasis Masyarakat. Bandung: Alfabeta.

Widjaja, P. (2013). Kampung-Kota Bandung. Yogjakarta: Graha Ilmu.

Wahyudi, J. (2019). Emisi Gas Rumah Kaca dari Pembakaran Terbuka Sampah Rumah Tangga Menggunakan Model IPCC. Jurnal Litbang: Media Informasi Penelitian, Pengembangan dan IPTEK, 15(1), 65-76.

\section{BIODATA PENULIS}

Suroso, lahir pada tanggal 19 Maret 1966 di Kabupaten Pati. Pendidikan Magister Perencanaan Kota dan Daerah, Universitas Gajah Mada. Bekerja sebagai Peneliti Madya di Badan Perencanaan Pembangunan Daerah Kabupaten Pati. 
